\title{
Non-Parasitic Chyluria: A Rare Experience
}

\author{
Faisal Ahmed ${ }^{*}$ \\ 'Department of Paediatrics and Neonatology \\ Imperial Hospital \\ Chattogram, Bangladesh.
}

\begin{abstract}
Chyluria is the passage of chyle in the urine. The cause seems to be the rupture of retroperitoneal lymphatics into the pyelocaliceal system, giving urine a milky appearance. This condition if left untreated leads to significant morbidity because of hematochyluria, recurrent renal colic, nutritional problems due to protein losses and immunosuppression resulting from lymphocyturia.
\end{abstract}

Key words: Chyluria; Lymphatic; Pyelocaliceal system.

\section{INTRODUCTION}

Chyluria is the passage of chyle in the urine. The cause seems to be the rupture of retroperitoneal lymphatics into the pyelocaliceal system, giving urine a milky appearance ${ }^{1-5}$. This communication is caused by the obstruction of lymphatic drainage proximal to intestinal lacteals, resulting in dilatation of distal lymphatics and the eventual rupture of lymphatic vessels into the urinary collecting system ${ }^{5-7}$. This condition if left untreated it leads to significant morbidity because of hematochyluria, recurrent renal colic, nutritional problems due to protein losses and immuno suppression resulting from lymphocyturia. Various conservative measures like bed rest, high fluid intake, low-fat diet, fat-containing medium-chain triglycerides have been described. Chyluria may be classified as mild, moderate, or severe. Many sclerosing agents have been tried as silver nitrate, povidone iodine diluted in distillated water or pure. Povidone iodine with or without dextrose solution as a sclerosing agent was used successfully in a few studies.

\section{CASE REPORT}

A boy of 11 year and 6 month of age presented at OPD of Imperial Hospital, Chattogram on 9th August 2019, with the H/O passage of milky urine, mostly in the morning two years without any other complaint. The patient had medical history negative for major diseases. His vitals are within normal limit and no abnormality noticed in systemic examination. He had been treated as a case of phosphoturia with phosphate binder and high dose of Vit D without any improvement for two years though his all biochemical profile were within normal limit.

Figure 1 : Morning urine sample (Milky urine).

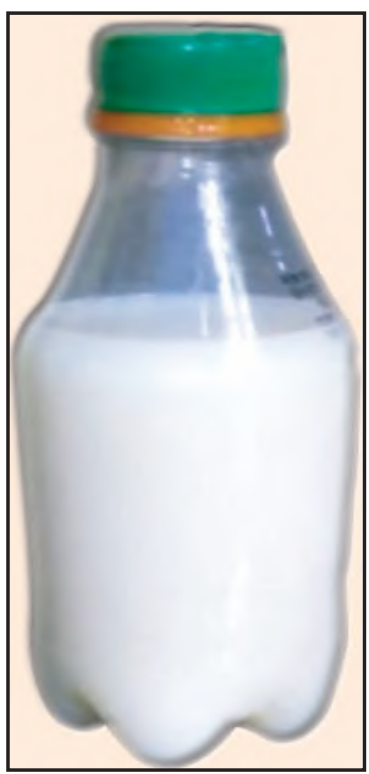


We have investigated him again and reports are :

Table I : Urine analysis of patient.

\begin{tabular}{lll} 
Name of investigation & Result & Reference range \\
Urine analysis & Protein $2+$ with few & \\
& RBC without pus cell & \\
24 hours Phosphate & $351 \mathrm{mg} / 24 \mathrm{hrs}$ & $<1000$ \\
24 hours calcium & $62 \mathrm{mg} / 24 \mathrm{hrs}$ & $100-300$ \\
ACR & 160.54 & $<2.5$ \\
Urinary total protein & $6357 \mathrm{mg} / \mathrm{L}$ & $10-140$ \\
Urinary micro-albumin & $4320 \mathrm{mg} / \mathrm{L}$ & $<20$ \\
Urinary Triglycerides & $221 \mathrm{mg} / \mathrm{L}$ & \\
Urinary Cholesterol & $8 \mathrm{mg} / \mathrm{dl}$ & \\
\hline
\end{tabular}

Source : Hospital records of patient.

Table II : Haematological investigations of patient.

$\begin{array}{llr}\text { Name of investigation } & \text { Result } & \text { Reference range } \\ \text { CBC } & \mathrm{Hb}-13.1 \mathrm{gm} / \mathrm{dl} \text {,ESR-14 } & \\ \text { RBS } & 5.6 \mathrm{mmol} / \mathrm{L} & \\ \text { S.Urea } & 14 \mathrm{mg} / \mathrm{dl} & \\ \text { S.Creatinine } & .59 \mathrm{mg} / \mathrm{dl} & \\ \text { ALP } & 297 \mathrm{U} / \mathrm{L} & 129-417 \\ \text { Vit D2 and D3 } & 22.6 \mathrm{ng} / \mathrm{ml} & 20-50 \\ \text { S. calcium } & 10.1 \mathrm{mg} / \mathrm{dl} & \\ \text { S. Phosphate } & 4.5 \mathrm{mg} / \mathrm{dl} & 3.5-5.4 \\ \text { PTH } & 48 \mathrm{pg} / \mathrm{ml} & 12-72 \\ \text { S. albumin } & 3.5 \mathrm{gm} / \mathrm{dl} & \\ \text { S. Cholesterol } & 151 \mathrm{mg} / \mathrm{dl} & <200 \\ \text { S. triglyceride } & 145 \mathrm{mg} / \mathrm{dl} & <150 \\ \text { S. electrolytes } & \text { Normal } & \end{array}$

Source: Hospital records of patient.

Table III : Other investigations of patient.

\begin{tabular}{ll} 
Name of investigation & Result \\
ICT for Filaria & IgM and IgG- Negetive \\
Tuberculin Test & Negetive \\
Complement C3 and C4 & Normal \\
ANA & Normal \\
\hline
\end{tabular}

Source: Hospital records of patient.

\section{Radiology and Imaging}

- X-ray Chest- Normal

- USG Whole Abdomen- Normal

- MRI of Pelvis : Diffuse meshwork of tubular tortuous fluid field structure within the retroperitonium (Encasing aorta, IVC, more along anteromedial to right renal region upto upper ureter) extending along both common iliac vessels and visible part of pelvis lateral to urinary bladder.

- Impression : Lymphangiectasis involving retroperitonium and pelvic region.

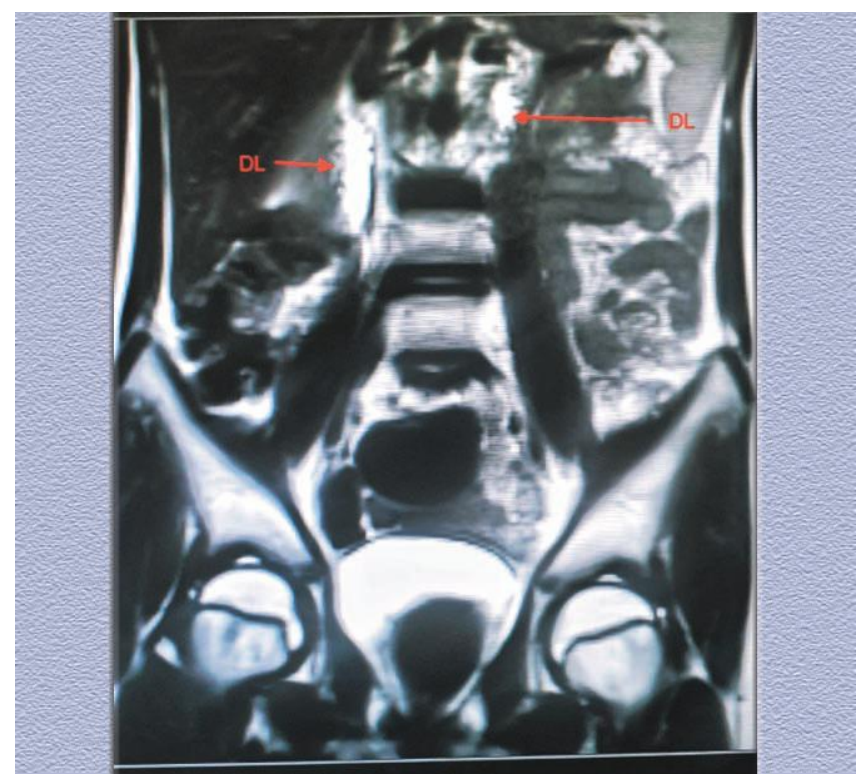

Figure 2 : Diffuse meshwork of tubular tortuous fluid field structure within the retroperitonium (Encasing aorta, IVC, more along anteromedial to right renal region upto upper ureter).

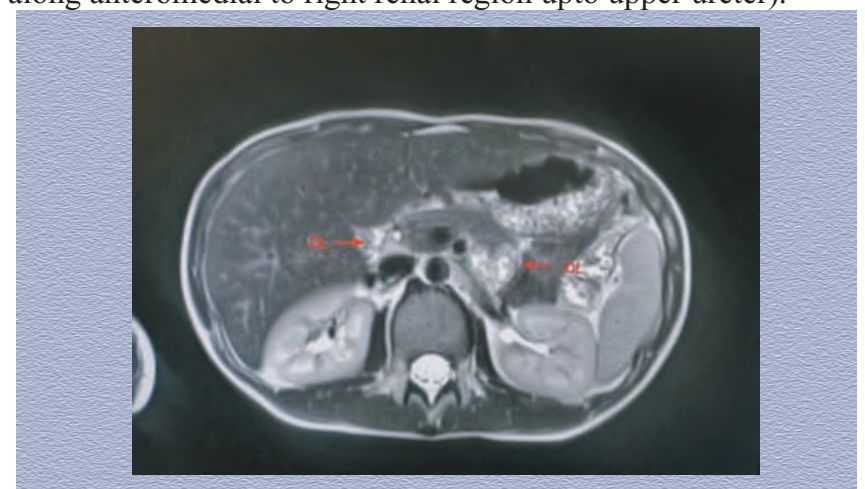

Figure 3 : Diffuse meshwork of tubular tortuous fluid field structure within the retroperitonium.

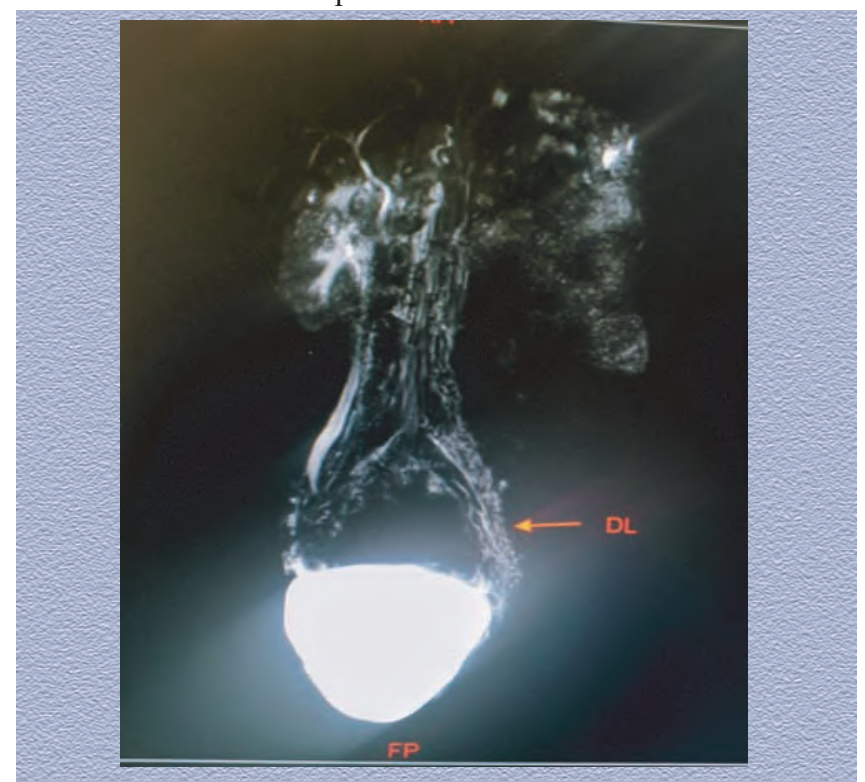

Figure 4 : Diffuse meshwork of tubular tortuous fluid field structure extending along both common iliac vessels and visible part of pelvis lateral to urinary bladder. 


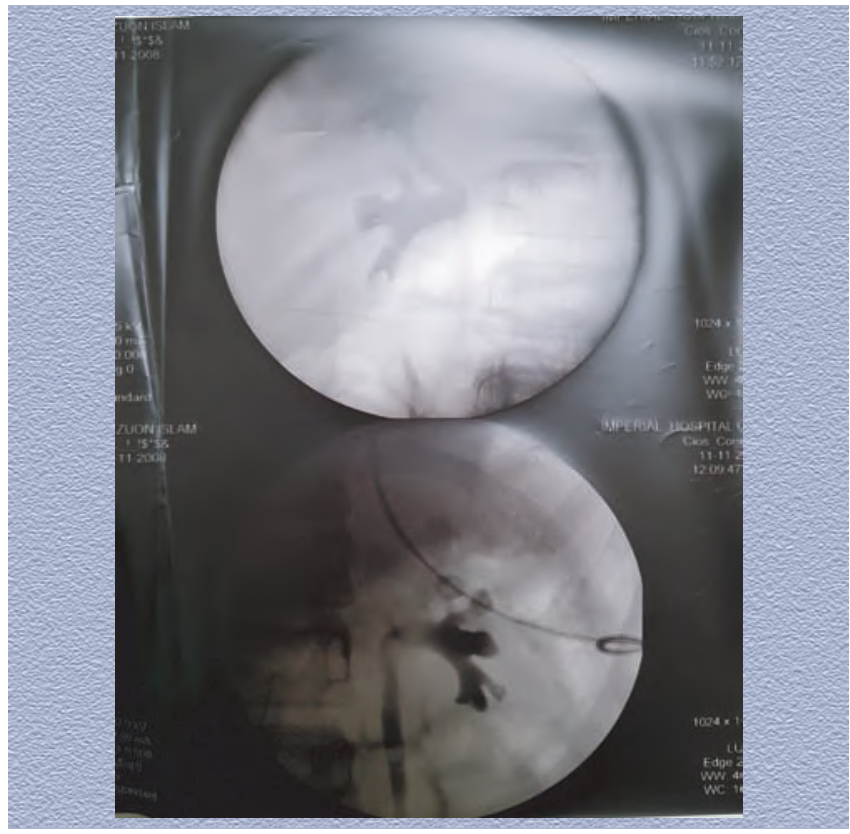

Figure 5 : Renal pelvic installation of sclerosant agents.

\section{DISCUSION}

The passage of large amount of chyle in the urine is known as chyluria. Chyle is a combination of proteins, emulsified fat and fibrin. Chyluria is classified as parasitic and nonparasit$\mathrm{ic}^{8,9}$. The parasitic one is seen most commonly in endemic areas such as India, China, Japan, Southeast Asia, tropical subSaharan Africa and South America. Wucheraria bancrofti is considered to be the parasitic cause for chyluria in these endemic areas. Other nonparasitic causes of chyluria include tuberculosis, congenital anomalies, trauma, post-surgery infections and malignancy. The cause of the disease is due to the obstruction and the rupture of the lymphatic system into the urinary system. The fistulous communication can occur at the renal pelvis, ureter, bladder or the prostatic urethra. The most common site is the renal fornix. The symptoms of chyluria are renal colic due to the passage of milky-white urine along with clots, dysuria, hematuria and urinary tract infections. In some severe forms, the disease could cause significant weight loss, cachexia, malnutrition, hypoproteinemia and immuno suppression.

The clinical diagnosis is confirmed by urine analysis for triglyceride-rich fatty emulsion with proteinuria. Additional investigation as complete blood test is required. To exclude other urological causes an abdominal ultrasound can be performed. Instead of lymphangiograpy other noninvasive method with equal accuracy is used: lymphoscintigraphy using 99m Tcnanocolloid. CT and MRI have also been useful in making the diagnosis. Other important evaluation that must be done are cystoscopy and retrograde pyelography after a heavy fat meal to confirm the site and side of the lymphatic-urinary fistula. Different types of treatment were tried in patients affected by chyluria. Renal pelvic instillation of sclerosant agents is a minimally invasive treatment for chyluria. Different type of sclerosant agents were used: silver nitrate 1-3\%, sodium iodide $1-25 \%$, potassium bromide $10-25 \%$, dextrose $50 \%$, urograffin $76 \%$, and hypertonic saline $22-25 \%$. These sclerosant agents induce an inflammatory reaction in the lymphatics. Initially they lead to chemical lymphangitis and edema of lymphatic channels. Later fibrosis and blockage of lymphatics occur, leading to closure of lymphatic pelvic communication. In the past, silver nitrate was commonly used in concentration ranging from $0.1-3 \%$ but it was abandoned due to its toxicity. Other authors described their experience using instillation of povidone iodine solution alone or combined with dextrose. Shanmugam et al. used a single instillation of povidone iodine in 5 patients, all the patients treated were free of symptoms at the 6-month follow-up ${ }^{10}$. Goel et al in a prospective randomized study on 106 patients divided in three groups (First group treated with $1 \%$ silver nitrate, second group treated with $0.2 \%$ povidone iodine and third group treated with $50 \%$ dextrose all at $8 \mathrm{~h}$ intervals for 3 days) underwent instillation of the solution at $8 \mathrm{~h}$ for 3 days, the authors demonstrated that povidone iodine was as effective as silver nitrate ${ }^{11}$. Nandy et al have used a combination of $5 \mathrm{~mL}$ of povidone iodine with $5 \mathrm{~mL}$ of $50 \%$ dextrose with complete recurrence in $87 \%$ of the patients $^{12,13}$.

\section{CONCLUSION}

Non-Parasitic Chyluria, a rare experience in our centre. We have instilled $10 \%$ povidone iodine plus $10 \%$ dextrose solution as a sclerosant into the renal pelvis which is safe, effective and associated with minimal morbidity.

Patient is now under follow up showing gradual improvement .

\section{ACKNOWLEDGMENT}

Dr. Azfar Uddin Shaikh, Dr. Mohammad Ibrahim, Dr. Muhammad Akram Hossain, Imperial Hospital, Chattogram, Bangladesh.

\section{DISCLOSURE}

The author declared no competing interest. 


\section{REFERENCES}

1. Yamauchi S. Chyluria : A Clinical, laboratory and statistical study of 45 personal cases observed in Hawaii. J Urol. 1945;54:318-347.

2. Diamond E, Schapira HE. Chyluria - A review of the literature. Urology. 1985;26:427-431.

3. WHO Expert Committee on Filariasis. Lymphatic filariasis: The disease and its control. Fifth report of the WHO expert committee on Filariasis. WHO expert committee on Filariasis. WHO Tech Rep Ser. 1992;821:1-71.

4. Akisada M, Tani S. Filarial chyluria in Japan. Lymphography, etiology and treatment in 30 cases. Radiology. 1968;90:311-317.

5. Koo CG, Van Langenberg A. Chyluria. A clinical study. J R Coll Surg Edinb. 1969;14:31-41.

6. Akisada M, Tani S. Filarial chyluria in Japan. Lymphangiography, etiology and treatment in 30 cases. Radiology. 1963;81:473.

7. Nunez Mora C, Carcamo Valor P, deCabo Ripoll M, Kabani MH, Martinez Pinerio Carames JA. Recurrent nonparasitic chyluria. Arch Esp Urol. 1998;51(9):932-934.

8. Tan L.B., Chiang C.P., Huang C.H. Experiences in the treatment of chyluria in Taiwan. J Urol. 1990;144:710-713. [PubMed] [Google Scholar].

9. Singh I., Dargan P., Sharma N. Chyluria - a clinical and diagnostic stepladder algorithm with review of literature. Indian J Urol. 2004;20:79-85. [Google Scholar].

10. Shanmugan T.V., Prakash J.V., Sivashankar G. Povidone iodine used as a sclerosing agent in the treatment of chyluria. Br J Urol. 1998;82:587. [PubMed] [Google Scholar].

11. Goel S., Mandhani A., Srivastava A. Is povidone iodine an alternative to silver nitrate for renal pelvic instillation chemotherapy in chyluria? BJU Int. 2004;94:1082-1085. [PubMed] [Google Scholar].

12. Nandy P.R., Dwivedi U.S., Vyas N. Povidone iodine and dextrose solution combination sclerotherapy in chyluria. Urology. 2004;64:1107-1109. [PubMed] [Google Scholar].

13. Andrea Guttilla, Paolo Beltrami, Laura Bettin, Andrea Galantini, Fabrizio Dal Moro, Vincenzo Ficarra, and Filiberto Zattoni Non-Parasitic Chyluria: Our Experience With Sclerotherapy With Solution of Povidone-Iodine and Destrose and A Review of the Literature. 2016; 8: 28-30. Published online 2016 Jun 24. doi: 10.1016/j.eucr.2016.05.010. 